65 (1): 2020

63-74

\title{
CALCULATION OF SOUND INSULATION OF SOFTWOOD SAMPLES AT NORMAL INCIDENCE AND COMPARISON WITH EXPERIMENTAL DATA
}

\author{
Zehui Ju, Qian He, Tianyi Zhan, Haiyang Zhang, Lu Hong, Xiaoning Lu \\ Nanjing Forestry University \\ Nanjing, PR China \\ (Received April 20I9)
}

\begin{abstract}
The acoustic simulations were carried out for softwood and composites in order to evaluate their sound properties. Theoretical value of sound insulation was predicted by regarding the substances in the wood cell wall as equivalence to specific medium based on Biot model, and the wood microscopic characteristics, such as the length and diameter of tracheid, diameter of pit, and porosity, were taken into account for determining the equivalent density and bulk modulus of wood. By comparing the tested and predicted values of sound insulation, the conclusions were drawn as follows: the predicted values of sound insulation were significantly correlated with the tested values for wood and wood composites. As for Masson pine, the adjacent of earlywood and latewood was considered as sandwich structure for the calculation of sound insulation. The transfer function involved in sound insulation simulation provided an effective method to characterize the sound insulation volume of wood and wood composite in construction and decoration areas.
\end{abstract}

KEYWORDS: Sound insulation simulation, equivalent medium, transfer function, wood microscopic characteristics, earlywood, latewood.

\section{INTRODUCTION}

Wood is one of the most environmental renewable building materials, which has been widely utilized in construction, transportation and decoration industry (Smardzewski 2009, Klašnja et al. 2008). Sound insulation has been investigated for a long time as one of the most crucial and interesting issue among the building environments (Beranek 1960, 1971). The traditional building insulation materials consisted of dense and homogeneous material. The sound insulation of single material increased with the increase of density, which conformed to the law of mass action (Shuku and Ishihara 1973). The gas mainly permeated through the tracheid pore in softwood, 
of which the percentage was over 90\% (Bao and Hou 2001, Watanabe and Norimoto 2000). The gas permeability in softwood was closely related with its flowing characteristics and rules in tracheids (Zhan 2014, Liu et al. 2012). In hence, it was significance to investigate the sound insulation of wood defined as the porous structure material. In the 1970s, the sound insulation performance of porous acoustic materials has been widely studied, mainly focusing on the sound insulation theory and materials (Whole and Elmallawany 1969). From the aspect of the sound insulation theory, António proposed a new ring structure material, established acoustic model by the traditional acoustic theory, and compared the theoretical value with the test sound insulation of plate material as the same time (António et al. 2004). Tadeu considered fully the coupling effect between the air and medium of the acoustic material by ignoring the thickness of material, and established the analysis model of plate material (Tadeu et al. 2004). Lee established a new method to evaluate the sound transmission loss of multilayer composite material by modifying the transfer matrix (Lee and Xu 2009). From the perspective of kinds of sound insulation material, the multi-layer gypsum board insulation materials were studied by Matsumoto et al. (2006). The results showed that sound insulation performance of multilayer composite significantly improved as that of layer increased from 2-lay to 4-lay by the different characteristics of different layers of the composite. From the aspect of theory of wood sound insulation, the microscopic characteristics of wood played a significance role in the sound insulation theory. However, it has been rarely investigated by researchers as a porous material especially involved in the model of the wood sound insulation.

According to the microscopic characteristics of wood materials, the length and diameter of tracheids, the diameter of pits and porosity were considered as the influencing factors of wood sound insulation model. The special flow resistance of wood material was used to modify the model, and the theory was applied to the simulation of softwood sound insulation. The sound insulation of Chinese fir and Masson pine was measured by experimental method under wide frequency and compared with the predicted value of the model.

\section{Sound insulation simulation}

The material was assumed to be transversely infinite and the sound wave was perpendicular to the surface of the plate in air medium. The pi represented the incident wave, the pr represented the reflected wave, and the pt represented the transmitted wave. The wood frame was assumed as a rigid body. The sound propagation in wood can be considered as a fluid motion, which can be equivalent to the calculation of fluid model. The sound propagation theory of Biot elastic porous medium was applied in the model. Besides, the effect of viscosity between air and pore wall and the effect of heat exchange were also considered, which were described in the Zwikker model and Kosten model respectively (Zwikker and Kosten 1949, Biot 1956, Allard 1993, Wilson 1993). The $\rho$ represented equivalent density $\left(\mathrm{kg} \cdot \mathrm{m}^{-3}\right)$ and the $K$ represented equivalent bulk modulus (MPa). Allard proposed that the function of $G_{J}\left(B^{2} \omega\right)$ could be replaced by the $F\left(B^{2} \omega\right)$ in the Stin-son model (Allard 1993), so the $F\left(B^{2} \omega\right)$ can be obtained in the Johnson model. Meanwhile, the feature size $\Lambda(\mathrm{m})$ was included and the expression of $G_{J}(\varpi)$ was easier than that of $G_{J}(\omega)$ to calculate. So the equivalent density $\rho$ in Johnson model and equivalent bulk modulus $K$ can be calculated with the following Eqs.:

$$
\begin{aligned}
& \rho=\rho_{0} \alpha_{\infty}\left(1+\frac{\sigma \phi}{j \alpha_{\infty} \rho_{0} \omega} G_{J}(\varpi)\right) \quad\left(\mathrm{kg} \cdot \mathrm{m}^{-3}\right) \\
& K=\frac{\gamma P_{0}}{\gamma-(\gamma-1)\left[1+\frac{\sigma \phi}{j B^{2} \omega \rho_{0} \alpha_{\infty}} G_{J}^{\prime}\left(B^{2} \omega\right)\right]^{-1}}
\end{aligned}
$$


The $\rho_{O}$ was the density of air $\left(\mathrm{kg} \cdot \mathrm{m}^{-3}\right)$ and $P_{O}$ was the air pressure $(\mathrm{MPa})$. The $\gamma$ was the ratio of the specific heats of air at constant pressure and constant volume and $B^{2}$ was the Prandtl constant. The $\sigma, \phi$ and $\omega$ represented the flow resistance of porous material $\left(\mathrm{Pa} \cdot \mathrm{s} \cdot \mathrm{m}^{-2}\right)$, the porosity and the angular velocity $\left(\mathrm{rad} \cdot \mathrm{s}^{-1}\right)$ respectively. The $\alpha \infty$ was tortuosity.

$$
\begin{aligned}
& G_{J}^{\prime}\left(B^{2} \omega\right)=\left(1+\frac{4 j \alpha_{\infty}^{2} \eta \rho_{0} \omega B^{2}}{\sigma^{2} \Lambda^{2} \phi^{2}}\right)^{\frac{1}{2}} \\
& G_{J}(\varpi)=\left(1+\frac{4 j \alpha_{\infty}^{2} \eta \rho_{0} \omega}{\sigma^{2} \Lambda^{2} \phi^{2}}\right)^{\frac{1}{2}} \\
& \Lambda=\frac{1}{\mathrm{c}}\left(\frac{8 \eta \alpha_{\infty}}{\sigma \phi}\right)^{\frac{1}{2}} \\
& k_{0}=\omega / c_{0}
\end{aligned}
$$

In this study, the standard state $\left(\right.$ at $18^{\circ} \mathrm{C}, 103.3 \mathrm{kPa}$, air parameter $\eta=1.84 \times 10-5 \mathrm{~kg} \cdot \mathrm{m}^{-1} \mathrm{~s}^{-1}$, $\gamma=1.4, \mathrm{~B} 2=0.71)$ was used in the simulation. The $\mathrm{c}$ was sound wave velocity $\left(\mathrm{ms}^{-1}\right)$ and $k_{O}$ was the wave number inside wood. The $\rho_{0}, c_{0}$ and $k_{0}$ were the corresponding amount in the condition of air respectively. The $\mathrm{d}$ represented the thickness of wood $(\mathrm{m})$ and $\mathrm{k}$ was the number of wood (Song and Bolton 2000, Zhang et al. 2010, Varivodina et al. 2010, Buksnowitz et al. 2010). The $\eta$ was the shear viscosity of air (Pa.s) and the $r$ was radius of the pore (m). For circular pores, $c=1$. The flow resistance of porous material can be characterized by the degree of difficulty of acoustic wave entering the material. The greater the flow resistance is, the more difficult the wave enters the material. However, there were still huge differences from the aspect of micro-characteristics in wood. The flow resistance of wood should be introduced to better predict the wood sound insulation (Bao and Hou 2002):

$$
\sigma=\frac{n * n_{p t} *(1-b) * \pi * r^{4} * L *(1-\alpha)}{D_{e}^{2} * 8 * \eta * L_{p m}} * 1.013 * 10^{6} \quad\left(\mathrm{~Pa} \cdot \mathrm{s} \cdot \mathrm{m}^{-2}\right)
$$

$A=D_{e}^{2}$, The $D_{e}$ was the tracheid diameter (m), A was the cross-sectional area of tracheids $\left(\mathrm{m}^{2}\right)$, npt was the number of pits, $n$ was the average number of micro pit membrane in each pit, $b$ was the occlusion rate of pits, $r$ was average radius of micro pit membrane $(\mathrm{m})$ and $L$ was average length of tracheid (m). The layer $i$ material was considered as the object of study, the transfer relationship between sound pressure $p(\mathrm{MPa})$ and velocity $v\left(\mathrm{~m} \cdot \mathrm{s}^{-1}\right)$ at the point $M_{i}$ and $M_{i+1}$ were expressed as:

$$
\begin{aligned}
& {\left[\begin{array}{l}
p_{M_{i}} \\
v_{M_{i}}
\end{array}\right]=T_{i}\left[\begin{array}{l}
p_{M_{i+1}} \\
v_{M_{i+1}}
\end{array}\right]} \\
& T_{i}=\left[\begin{array}{cc}
\cos \left(k_{i} d_{i}\right) & j \sin \left(k_{i} d_{i}\right) Z_{c} \\
j \sin \left(k_{i} d_{i}\right) / Z_{c} & \cos \left(k_{i} d_{i}\right)
\end{array}\right] \\
& k_{i}=\omega\left(\frac{\rho_{i}}{K_{i}}\right)^{\frac{1}{2}}
\end{aligned}
$$

The $d_{i}$ was the thickness of the material layer $(\mathrm{m})$, and $k_{i}$ was the wave number of the material, $Z_{c}$ was the characteristic impedance of air. The relationship the interfaces of the material can be established as follows: 


$$
\left[\begin{array}{c}
p_{i}+p_{r} \\
\left(p_{i}-p_{r}\right) \frac{k_{0}}{\omega \rho_{0}}
\end{array}\right]=\prod_{i=1}^{n} T_{i}\left[\begin{array}{c}
p_{t} \\
p_{t} \frac{k_{0}}{\omega \rho_{0}}
\end{array}\right]
$$

The $k_{O}$ and $\rho_{O}$ were the wave number and density of air medium. The total transfer matrix of the composite plate were obtained:

$$
\left[\begin{array}{c}
p_{i}+p_{r} \\
\left(p_{i}-p_{r}\right) \frac{k_{0}}{\omega \rho_{0}}
\end{array}\right]=\left[\begin{array}{ll}
T_{1,1} & T_{1,2} \\
T_{2,1} & T_{2,2}
\end{array}\right]\left[\begin{array}{c}
p_{t} \\
p_{t} \frac{k_{0}}{\omega \rho_{0}}
\end{array}\right]
$$

The transmission coefficients of multilayer materials can be obtained as follows:

$$
t_{p}=\frac{2}{T_{1,2}+T_{2,2}+T_{1,2} \frac{k_{0}}{\omega \rho_{0}}+T_{2,1} \frac{\omega \rho_{0}}{k_{0}}}
$$

The sound insulation $(\mathrm{R})$ of the multilayer material was expressed as:

$$
R=20 \lg \left|\frac{1}{t_{p}}\right|
$$

\section{MATERIAL AND METHODS}

\section{Materials}

The Chinese fir (Cunninghamia lanceolata Lamb.) was collected from Xunyi County of Shanxi province of China with $0.22 \mathrm{~m}$ diameter and $4 \mathrm{~m}$ length. The average air-dried density was $320 \mathrm{~kg} \cdot \mathrm{m}^{-3}$. The Masson pine (Pinus massoniana Lamb.) was collected from Guangdong Province of China with $0.24 \mathrm{~m}$ diameter and $4 \mathrm{~m}$ length. Its average air-dried density was $460 \mathrm{~kg} \cdot \mathrm{m}^{-3}$. The Chinese fir block and the Masson pine block were T-R surfaces.

Material 1 represented single ply testing sample of fir. Material 2 represented single ply testing sample of Masson Pine. Material 3 represented two-ply Chinese fir. The PF adhesive was self-made in the laboratory and utilized in the fabrication of wood composites. Material 4 represented two-ply sample of fir and Masson, the incident surface of sound wave was Chinese fir in the test. The PF adhesive was also used in Material 4. Material 5 was the same structure of Material 4, but the incident surface of sound wave was Masson pine. Material 6 represented by three-ply sample of Chinese fir.

\section{Methods}

Scanning electron microscope (SEM)

The sample of $5 \times 5 \times 5 \mathrm{~mm}$ was cut from disc. The samples of the three sections were cut flat by a blade. The samples were stored at room temperature until processing for SEM (TM-1000, Japan) observation. The samples were coated with osmiun tetroxide $\left(\mathrm{O}_{\mathrm{S}} \mathrm{O}_{4}\right)$ in a Plasma Coater (HPC-1SW, Vacuum Device Inc) before imaging.

\section{Mercury intrusion porosimetry (MIP)}

A disc (15 $\mathrm{mm}$ diameter, $10 \mathrm{~mm}$ thickness) was cut from the middle of each material. The samples were dried in an oven at $103 \pm 2{ }^{\circ} \mathrm{C}$ for 24 hours. The MIP characterizing process 
Vol. 65 (1): 2020

employed an Autopore TM IV 9500 Automated Mercury Porosimeter (Micromeritics Instrument Corp., US). The pore distribution was determined with the Washburn equation (Suleiman et al. 1999).

\section{Test instrument of sound insulation}

The sound absorption test was carried out according to Chinese Standard GB/T18696.12004. The test system was Beijing prestige R-Cabin test system.

\section{RESULTS AND DISCUSSION}

\section{Wood microscopic characteristics by SEM}

It was found that the gas permeability of softwood was closely related to its flow characteristics and regularities in the tracheid. The SEM of wood microscopic characteristics was described in the Fig. 1. The arrangement of tracheids in softwood was uniform, which fited the requirement of theoretical simulation. So the microscopic characteristics of wood should be introduced into the theory to modify the model. The characteristic of tracheids and pits were described in the Tab. 1.
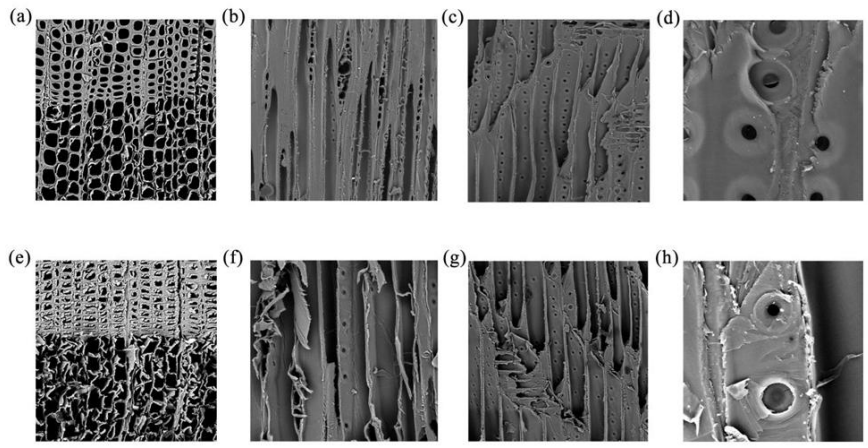

Fig. 1: Chinese fir: (a) transverse section ( $\times 300)$, (b) tangential section $(\times 300)$, (c) radial section $(\times 300),(d)$ pit and aspirated pit $(\times 2000)$. Masson Pine: (e) transverse section $(\times 300)$, ( $f$ ) tangential section ( $\times 300),(\mathrm{g})$ radial section $(\times 300),($ b) pit and aspirated pit $(\times 2000)$.

Tab. 1: Weighted average of some structural parameters of tracheids from sampling measurement.

\begin{tabular}{|c|c|c|c|c|c|c|c|c|c|c|c|c|}
\hline & $\begin{array}{l}L_{p m} \\
(\mu \mathrm{m})\end{array}$ & $\begin{array}{l}D_{e 1} \\
(\mu \mathrm{m}) \\
\end{array}$ & \multicolumn{2}{|c|}{$D_{e 2}(\mu \mathrm{m})$} & $\begin{array}{c}\alpha \\
(\%) \\
\end{array}$ & $\begin{array}{c}b \\
(\%) \\
\end{array}$ & $\begin{array}{c}D_{1} \\
(\mu \mathrm{m}) \\
\end{array}$ & $\begin{array}{c}D_{2} \\
(\mu \mathrm{m}) \\
\end{array}$ & $\begin{array}{c}D_{3} \\
(\mu \mathrm{m}) \\
\end{array}$ & $\begin{array}{r}D_{4} \\
(\mu \mathrm{m}) \\
\end{array}$ & $\begin{array}{c}n_{p t} \\
\text { (number) }\end{array}$ & $\begin{array}{c}n \\
\text { (number) } \\
\end{array}$ \\
\hline \multirow{2}{*}{ Material 1} & \multirow{2}{*}{ Chinese fir } & \multirow{2}{*}{4210.70} & & & \multirow{2}{*}{2.13} & \multirow{2}{*}{40.20} & \multirow{2}{*}{2.00} & \multirow{2}{*}{5.00} & \multirow{2}{*}{15.00} & \multirow{2}{*}{0.10} & \multirow{2}{*}{25} & \multirow{2}{*}{163} \\
\hline & & & \multicolumn{2}{|c|}{37.43} & & & & & & & & \\
\hline Material 2 & Masson Pine & 4502.90 & 45.23 & 44.83 & 2.40 & 56.80 & 5.00 & 9.00 & 20.00 & 0.20 & 20 & 155 \\
\hline \multirow{2}{*}{ Material 3} & Chinese fir & 4211.44 & \multicolumn{2}{|c|}{36.97} & 2.13 & 40.20 & 2.00 & 5.00 & 15.00 & 0.10 & 25 & 159 \\
\hline & Chinese fir & 4210.55 & \multicolumn{2}{|c|}{37.44} & 2.13 & 40.20 & 2.00 & 5.00 & 15.00 & 0.10 & 25 & 160 \\
\hline \multirow{2}{*}{ Material 4} & Chinese fir & 4255.40 & \multicolumn{2}{|c|}{37.56} & 2.13 & 40.20 & 2.00 & 5.00 & 15.00 & 0.10 & 25 & 155 \\
\hline & Masson Pine & 4512.43 & 45.43 & 44.83 & 2.37 & 55.67 & 5.00 & 9.00 & 20.00 & 0.20 & 20 & 154 \\
\hline \multirow{2}{*}{ Material 5} & Masson Pine & 4512.43 & 45.43 & 44.83 & 2.37 & 55.67 & 5.00 & 9.00 & 20.00 & 0.20 & 20 & 154 \\
\hline & Chinese fir & 4255.40 & \multicolumn{2}{|c|}{37.56} & 2.13 & 40.20 & 2.00 & 5.00 & 15.00 & 0.10 & 25 & 155 \\
\hline \multirow{3}{*}{ Material 6} & Chinese fir & 4215.77 & \multicolumn{2}{|c|}{37.00} & 2.13 & 40.20 & 2.00 & 5.00 & 15.00 & 0.10 & 25 & 167 \\
\hline & Chinese fir & 4216.50 & \multicolumn{2}{|c|}{37.50} & 2.13 & 40.20 & 2.00 & 5.00 & 15.00 & 0.10 & 25 & 165 \\
\hline & Chinese fir & 4250.7 & \multicolumn{2}{|c|}{37.46} & 2.13 & 40.20 & 2.00 & 5.00 & 15.00 & 0.10 & 25 & 163 \\
\hline
\end{tabular}


$L_{p m}$ - tracheid length; $D_{e}$ - tracheid diameter; $D_{e 1}$ - early wood tracheid diameter; $D_{e 2}$ - latewood tracheíd diameter; $\alpha$-percentage of tracheid overlap; $b$ - percentage of aspirated pit; $D_{1}$ - diameter of pitaperture; $D_{2}$ - torus diameter; $D_{3}$ diameter of pit membrane; $D_{4}$ - diameter of pore on pit membrane; $n_{p t}$ - number of pits on the over-lap face of tracheid; $n$ - number of pit membrane openings of a tracheíd.

\section{Determination of porosity and pore size by MIP}

The results of the MIP measurement were shown in Tab. 2. The test results were used to calculate the theoretical simulation of sound insulation.

Tab. 2: The MIP test results.

\begin{tabular}{|l|l|c|c|c|}
\hline \multicolumn{2}{|c|}{ Number } & Median pore & Porosity & Density \\
\cline { 3 - 5 } & diameter $(\mu \mathrm{m})$ & $(\%)$ & $\left(\mathrm{g} \cdot \mathrm{cm}^{-3}\right)$ \\
\hline Material 1 & Chinese fir & 37.5 & 77.424 & 0.32 \\
\hline Materia1 2 & Masson Pine & 45.2 & 65.54 & 0.45 \\
\hline \multirow{2}{*}{ Material 3 3} & Chinese fir & 37.1 & 76.4 & 0.32 \\
\cline { 2 - 5 } & Chinese fir & 37.6 & 77.2 & 0.32 \\
\hline \multirow{2}{*}{ Materia1 4 } & Chinese fir & 37.2 & 76.4 & 0.32 \\
\cline { 2 - 5 } & Masson Pine & 45.1 & 67.2 & 0.46 \\
\hline \multirow{2}{*}{ Material 5 } & Masson Pine & 45.1 & 67.2 & 0.46 \\
\cline { 2 - 5 } & Chinese fir & 37.2 & 76.4 & 0.32 \\
\hline \multirow{3}{*}{ Material 6 } & Chinese fir & 37.5 & 76.4 & 0.32 \\
\cline { 2 - 5 } & Chinese fir & 37.1 & 77.1 & 0.32 \\
\cline { 2 - 5 } & Chinese fir & 38.0 & 76.9 & 0.32 \\
\hline
\end{tabular}

\section{Sound insulation simulation of single layer Chinese fir}

The test values obtained from the three tests were compared with the theoretical simulation values. The analog 1 curve was obtained by the theoretical model based on classical flow resistance, the analog 2 curve was calculated by the theoretical model of flow resistance based on wood characteristics, and the curves were corrected simultaneously. As can be seen, the analog 2 was better to reflect the sound insulation of Chinese fir than the analog 1 (Fig. 2).

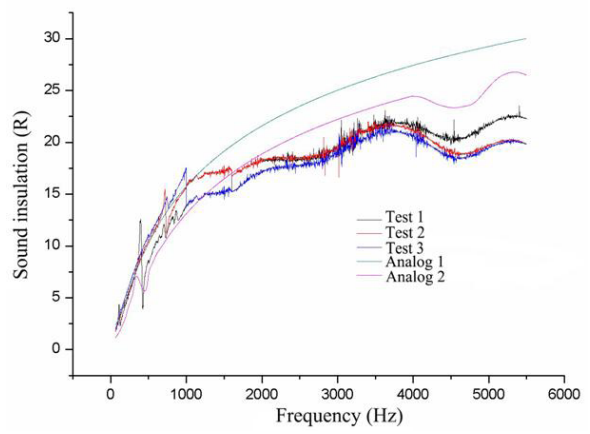

Fig. 2: Simulated sound insulation and measured value of Chinese fir.

As shown in Fig. 2, the sound insulation increased with the increase of frequency. The material was mainly controlled by the stiffness of the material at low frequency, so it was easy to reduce the sound insulation of the material by the resonance effect at low frequency. With the increase of frequency, the material was mainly affected by the law of mass. When the frequency of 
sound wave reached the critical frequency, there will be a coincidence effect, resulting in the low sound insulation at the high frequency. There were two main reasons that the sound insulation of materials at low frequency was lower than that at high frequency. (1) The characteristic pore size of wood was far smaller than the wavelength at low frequency. The sound wave was reflected when it propagated on the material surface. The wavelength of the high frequency was relatively smaller than that of the low frequency, so it was easy for sound wave to enter the interior of wood at high frequency. (2) The sound insulation process can be divided into two stages according to the frequency, i.e. isothermal process and adiabatic process. The isothermal process mainly occurred at the low frequency. The part of the sound energy was converted into heat energy under the action of friction resistance by the adhesion between the air and the internal pores. However, the process carried out heat exchange with the outside world by the long time, so that the material can maintain the isothermal process. For the high-frequency, it was mainly the adiabatic process. The action time of this process was relatively short, and the energy conversion was relatively fast, so the material cannot exchange energy with the outside world in the process. Therefore, the sound wave in the high-frequency can be considered as the adiabatic process.

With the increase of the frequency, the sound insulation decreased obviously at high frequency. The main reason was that the part of the sound wave was reflected back in the process of propagation. When the incident wave and the reflected wave were superposed, the coincidence effect was produced, and the sound insulation decreased.

The errors between the analog 1 and the analog 2 were mainly due to the fact that wood flow resistance can more accurately reflect the permeability of the gas in the wood. Analog 2 was more accurate than Analog 1. The reason was that the theoretical model based on wood flow resistance can more accurately reflect the propagation characteristics of sound wave in wood. There were some errors between the three test values in Fig. 2. The main reasons were that there was a certain gap between the sample and the test instrument in the experiment. At the same time, the flatness of the wood surface cannot be guaranteed, which led to errors in the low frequency range, but it can still reflect the sound insulation of wood. Analog 2 was related to three groups of test results. The error between the test and simulation value was large in the low frequency part, especially in the case of less than $315 \mathrm{~Hz}$. The main reason was that wood belonged to porous material, and the loss of sound transmission was small, which led to a large error of sound insulation. In addition, the resonance phenomenon of wood at low frequency led to the reduction of sound insulation, which also engendered the error between test and simulation value.

The error between the theoretical sound insulation and the test value was very small between $315-4000 \mathrm{~Hz}$. However, there was still error at frequency of more than $4000 \mathrm{~Hz}$. The main reasons were that there was a critical frequency of wood in this frequency range, and the material had a coincidence effect, which led to the reduction of sound insulation. In addition, the theoretical model only considered the radial flow resistance of wood, ignored the transverse and tangential flow resistance of wood. The critical frequency of Chinese fir was generated at $4520 \mathrm{~Hz}$. The coincidence effect was occurred at the interval of $4000-5000 \mathrm{~Hz}$, and the simulated values can be revised at this interval by repeating tests. Throughout the analog 2 curve, the simulation value still had errors by ignoring all the test errors. Research showed that the difference of earlywood and latewood of Chinese fir was small, and the classification was difficult, which was the main reason of the error of simulation value.

\section{Sound insulation simulation of single layer Masson pine}

As shown in Fig. 3, the test data obtained from the three tests were compared with the theoretical simulation values. The analog 1 curve was obtained by the theoretical model based on classical flow resistance. The analog 2 curve was calculated by the theoretical model of flow 
resistance based on wood characteristics. The earlywood and latewood of Masson pine were divided into two layers. The flow resistance characteristics of earlywood and latewood were introduced, and the theoretical model was modified to obtain the analog 3 curve. The analog 3 curve was correlated with the three test results respectively. The error was similar to that of Chinese fir. The error between the test and simulation value was large in the low frequency part (especially $<315 \mathrm{~Hz}$ ). The main reasons were that Masson belonged to porous material, and the loss of sound transmission was small, which led to a large error of sound insulation. In addition, the resonance phenomenon of wood at low frequency led to the reduction of sound insulation, which also produced the error between test and simulation value. The error between theoretical sound insulation property and the test value was very small in the range of $315-4000 \mathrm{~Hz}$. But there were still errors at frequencies of more than $4000 \mathrm{~Hz}$. The main reasons were that the critical frequency at high frequency of Masson pine led to the coincidence effect. Meanwhile, the theoretical model only considered the radial flow resistance of wood and the transverse and tangential flow resistance of wood was ignored. The critical frequency of Masson pine was generated at $4375 \mathrm{~Hz}$. The coincidence effect was occurred at the interval of $3500-5000 \mathrm{~Hz}$, and the simulated values can be revised at this interval by repeating tests.

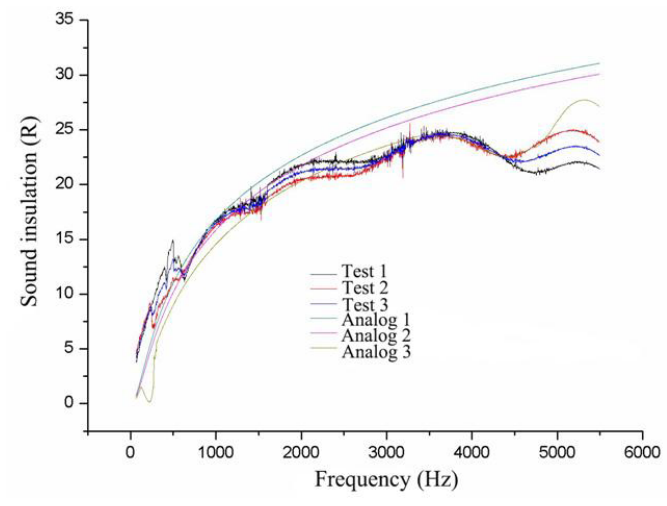

Fig. 3: Simulated sound insulation and measured value of Masson pine.

It was found that the sound insulation formula can be used to predict the sound insulation by the study of single board.

\section{Sound insulation simulation of two-ply of fir}

The comparison between the simulated and measured sound insulation of material 3 was shown in the Fig. 4. The analog 1 curve was obtained by the theoretical model based on classical flow resistance. The analog 2 curve was calculated by microscopic characteristics of wood and the correction of high-frequency error of material 3. The analog 2 curve perfectly reflected the sound insulation of fir double layer composite board. The main reason for the error between analog 1 and analog 2 was that the flow resistance based on the microscopic characteristics of wood can more accurately reflect the propagation characteristics of sound waves in wood. 


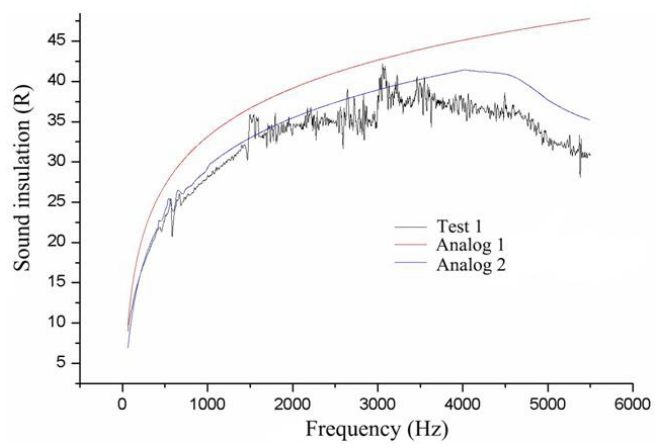

Fig. 4: Simulated sound insulation and measured value of two-ply of fir.

It was proved that the theoretical formula can better predict the sound insulation performance of fir double layer composite board. In the next composite plate experiment, the classical formula will not be used to predict the sound insulation performance of materials because the improved formula can better simulate the sound insulation of composite plate. In the case of ignoring the test error, the theoretical error still existed in the whole frequency range, which may be that the influence of the adhesive layer was not considered.

\section{Sound insulation simulation of two-ply of fir and Masson pine}

The simulation and test values of Material 4 and Material 5 were showed in Fig. 5. The test 1 curve was test value of Material 4. The test 2 curve is test value of Material 5. The microscopic characteristics of wood and the flow resistance characteristics of earlywood and latewood were introduced, the theoretical model was modified, and the analog 1 curve of Material 4 and the analog 2 curve of Material 4 were obtained.

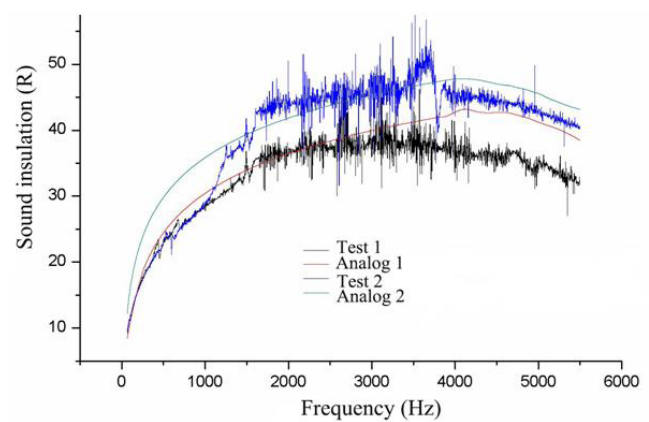

Fig. 5: Simulated sound insulation and measured value of two-ply of fir and Masson pine.

When the average density and modulus of Material 4 were the same as that of Material 5, the sound insulation varied with the surface density of the sample. The higher the surface density is, the better the sound insulation performance of the composite is. The increasing the surface density of the material had a positive significance to the sound insulation performance of the material. At the same time, it showed that the increase of the material surface density can effectively inhibit the anastomotic effect by the shallowness of the anastomotic valley. The main reason was related to the resonance frequency and critical frequency of the material. The high frequency of 
the sound wave was mainly absorbed by the interior of the material. For low-frequency, this part was absorbed by the surface of the material. With the increase of surface density, the attenuation of internal material increased and the attenuation of surface decreased. The results showed that using high-density material as the face-plate can effectively improve the sound insulation, but it did not work at low frequency. Therefore, the sound insulation performance could be affected by different surface panels.

\section{Single and double layer and the three layer of Chinese fir composite plate sound insulation simulation}

The simulation and test values of Material 1, 3 and 6 were displayed in the Fig. 6 . The test 1 curve was the test value of Material 6. The analog 1 curve was the simulation value of material 6 by the theoretical model of flow resistance based on wood characteristics. The test 2 curve was the test value of Material 3 and the analog 2 curve was the simulation value of Material 3. The test 3 curve was the test value of material 1 and the analog 3 was the simulation value of material 1.

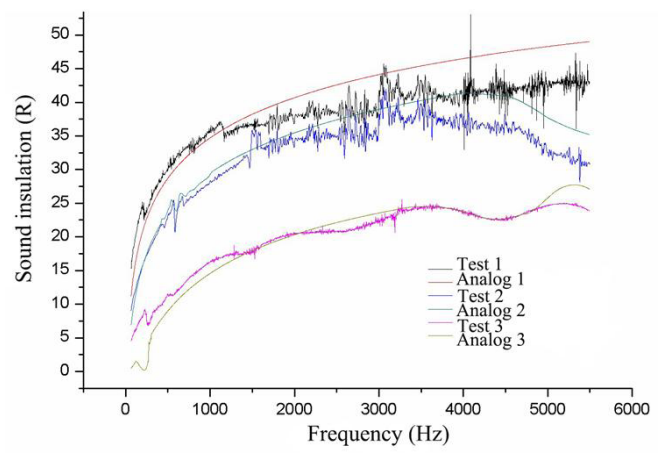

Fig. 6: Simulated sound insulation and measured value of Single and double layer and the three layer of Chinese fir composite plate.

It was found that the sound insulation increased significantly with the increase of the number of Chinese fir layers. The trend of the increase of sound insulation was more obvious in the middle and high frequency band $(>500 \mathrm{~Hz})$. The main reasons for this phenomenon were that the smaller the number of wood layers, the lower the flow resistance of the composite material, the easier the sound wave propagation, and the more able to penetrate the interior of the material. The flow resistance of the material increased with the increase of the number of wood layers. The force between the sound wave and the internal pores of the material increased with the increase of the flow resistance of the sound wave passing through the material. As a result, the sound energy loss increased when the sound wave propagated to the material. At the same time, it can be found that the critical frequency of the material shifted to the high frequency with the increase of the number of layers. The main reason was that the elastic modulus of the materials increased with the increase of the number of layers.

The more layers of composite materials, the greater the sound insulation. However, it was found that the increment of sound insulation decreased with the increase of composite layers by compared with three groups of data. In hence, increasing the thickness of material was not the effective method to improve the sound insulation performance, which was due to the coincidence effect shifting to the high frequency. At the same time, the increase of the number of layers cannot effectively suppress the resonance phenomenon. 


\section{CONCLUSIONS}

The simulation model of wood sound insulation was established by the classical theoretical model and the microscopic characteristics of wood. Theoretical value of sound insulation was predicted by regarding the substances in wood cell wall as equivalence to specific medium based on Biot model, and the wood microscopic characteristics were taken into account for determining the equivalent density and bulk modulus of wood. The adjacent of earlywood and latewood was considered as sandwich structure in the sound insulation calculation of Masson pine. The transfer matrix and theoretical calculation formula of sound insulation provided a valuable method for investigating the high performance wood composite insulating board. For the composite materials, the sound insulation could be effectively improved by using the high density material as surface panel, but it did not work at low frequency. Increasing the thickness of material was not an effective method to improve the sound insulation performance.

\section{ACKNOWLEDGEMENTS}

The authors gratefully acknowledge funding supports from the National Key R\&D Program of China (2017YFC0703501), the National Natural and Science Foundation (Nos. BK20170926 and BK20150878), the Postgraduate Research \& Practice Innovation Program of Jiangsu Province (KYCX18_0962). All authors contributed equally to this work.

\section{REFERENCES}

1. António, J., Godinho, L., Tadeu, A., 2004: Acoustic insulation provided by circular and infinite plane walls. Journal of Sound and Vibration 273(3): 681-691.

2. Allard, J.F., 1993: Propagation of sound in porous media: Modeling sound absorbing materials. Chapman \& Hall. London, 284pp.

3. Biot, M.A., 1956: Theory of propagation of elastic waves in a fluid-saturated porous solid-I: low-frequency range. Journal of the Acoustical Society of America 28: 168-178.

4. Bao, F.C., Hou, Z.Q., 2001: Gas flow resistance and permeability coefficient of conifer wood. Scientia Silvae Sinicae 37(4): 80-87.

5. Bao, F.C., Hou, Z.Q. 2002: Three dimensional flow resistance network of longitudinal gas permeation in coniferous wood. Scientia Silvae Sinicae 38 (4): 111-116.

6. Buksnowitz, C., Teischinger, A., Grabner, M., Müller, U., 2010: Tracheid length in Norway spruce (Picea abies (L.) Karst.) analysis of three databases regarding tree age, cambial age, tree height, inter-annual variation, radial distance to pith and log qualities. Wood Research 55(4): 1-13.

7. Beranek, L.L., 1960: Noise reduction. McGraw-Hill. New York, 752 pp.

8. Beranek, L.L., 1971: Noise and Vibration Control. McGraw-Hill. New York, 804 pp.

9. Lee, C.-R., Xu, Y., 2009: A modied transfer matrix method for prediction of transmission loss of multilayer acoustic materials. Journal of Sound and Vibration 326(1): 290-301.

10. Klašnja, B., Orlovič, S., Galić, Z., Drekić, M., 2008: Poplar biomass of high density short rotation plantations as raw material for energy production. Wood Research 53(2): 27-38.

11. Liu, X.-J., Liu, J.L., Xu, B.-J., Gao, W.-D., 2012: Acoustic analysis for a sound absorbing structure with multi-layered porous material. Journal of Vibration and Shock 31(5): 106-117. 
12. Matsumoto, T., Uchida, M., Sugaya, H., Tachibana, H., 2006: Development of multiple dry wall with high sound insulation performance. Applied Acoustics 67(6): 595-608.

13. Rowell, R.M., 1984: Penetration and reactivity of cell wall components. In: The chemistry of solid wood (ed. Rowell RM). American Chemical Society, Washington, Pp. 175-210.

14. Suleiman, B.M., Larfeldt, J., Leckner, B., Gustavsson, M., 1999: Thermal conductivity and diffusivity of wood. Wood Science and Technology 33(6): 465-473.

15. Shuku, T., Ishihara, K., 1973: The analysis of the acoustic field in irregularly shaped rooms by the finite element method. Journal of Sound and Vibration 29(1): 67-76.

16. Smardzewski, J., 2009: The reliability of joints and cabinet furniture. Wood Research 54(1): 67-76.

17. Song, B.H., Bolton, J.S., 2000: A transfer-matrix approach for estimating the characteristic impedance and wave numbers of limp and rigid porous materials. Journal of the Acoustical Society of America 107(3): 1131-1152.

18. Tadeu, A., António, J., Diogo, M., 2004: Sound insulation provided by single anddouble panel walls: a comparison of analytical solutions versus experimental results. Applied Acoustics 65(1): 15-29.

19. Varivodina, I., Kosichenko, N., Varivodin, V., Sedliačik, J., 2010: Interconnections among the rate of growth, porosity and wood water absorption. Wood Research 55(1): 59-66.

20. Whole, W., Elmallawany, A., 1969: Generalized model of application of statistical energy analysis for the sound propagation in a complicated structure. Journal of Sound and Vibration 40(2): 233-241.

21. Watanabe, U., Norimoto, M., 2000: Three dimensional analysis of elastic constants of the wood cell wall. Wood Research 87: 1-7.

22. Wilson, D.K., 1993: Relaxation-matched modeling of propagation through porous media, including fractal pore structure. Journal of the Acoustical Society of America 94: 1136-1145.

23. Zhang, Z.G., Zhang, X.L., Zhang, N., 2010: Study on sound insulation properties of materials by transfer matrix standing wave tube method. Materials Review 5: 118-121.

24. Zhan, P., 2014: Study on sound insulation properties of composite structures with air and porous materials. Applied Acoustics 33(5): 426-432.

25. Zwikker, B.C., Kosten, C.W., 1949: Sound absorbing materials. Elsevier publishing company. New York, 173 pp.

\author{
Zehui Ju, Qian He, Tianyi Zhan, Haiyang Zhang, Lu Hong, Xiaoning Lu* \\ Nanjing Forestry University \\ College of Materials Science and Engineering \\ NANJING 210037 \\ P.R. CHINA \\ *Corresponding author: luxiaoning@njfu.edu.cn
}

